\title{
Estudos comparativos da variabilidade na composição da resina da folha entre árvore parental e progênie de espécies selecionadas de Hymenaea
}

\author{
I. Comparação de populaçōes amazônicas e venezuelanas
}

\author{
Jean $\mathrm{H}$. Langenheim $\left({ }^{(}\right)$ \\ Will Stubblebine ( $\left.{ }^{(}\right)$ \\ Craig Foster ( $\left.{ }^{(}\right)$ \\ José Carlos Nascimento (")
}

\begin{abstract}
Resumo
Este estudo é parte de uma longa investigaçăo sobre a variação na composição da resina em leguminosas tropicais do genero Hymenaea e os possíveis papéis ecológicos que estas resinas desempenham nos ecossistemas tropicais. Este trabalho constitui o primeiro de uma série onde comparar-se-á a variação em composição entre árvore parental (ou "árvore mãe" como é também mencionada no decorrer deste trabalho) e progênie de diferentes espécies de Hymenaea na Hiléia Amazônica com outros ecossistemas tropicais. Aqui são apresentadas as bases gerais para estudos em ecologia química de resinas nos trópicos.

Foram estudados exemplares de $\mathbf{H}$. intermedia e H. parvifolia da Reserva Ducke, do Instituto Nacional de Pesquisas da Amazônia (INPA), próxima a Manaus, Amazonas, Brasil, e exemplares de $\mathbf{H}$. courbaril da Laguna de Los Patos, local adjacente a Estacion Biologica de Los Llanos, próximo a Calabozo, Guarico, Venezuela. Consistentes diferenças ocorreram na composição da resina (isto é, tipos químicos) entre árvores parentais e plântulas sobreviventes sob suas copas em $\mathbf{H}$. intermedia e H. parvifolia nas condições de floresta tropical úmida da Amazônia Central. Consideravelmente menor variabilidade ocorreu entre árvore parental e progênie em condiçōes de savana na Venezuela Central. Não se sabe se a composição da resina da folha modifica-se com mudanças ontogenéticas da árvore desde plântula até o estágio adulto. Todavia, o que parece significante é que sob condições de florestas tropicais úmidas, onde a maior pressão herbivora seria prevista, existe diferença gritante entre a composição da resina da folha da árvore mãe (parental) e sua progênie, bem como entre árvores adultas. Esta diversidade é hipotetizada através da seleção contra qualquer um ou ambos predadores sensiveis à distância e à densidade. Estes resuitados preliminares serâo analisados mais extensivamente em estudos subsequientes.
\end{abstract}

\section{INTRODUÇÃO}

O estudo da biossíntese, variação em composição e o papel das resinas nas leguminosas tropicais do gênero Hymenaea, tem sido parte de uma grande investigação na evolução de árvores produtoras de resina (Langenheim, 1964. 1966, 1967, 1969a, 1969b, 1972, 1973, 1975). Este trabalho foi iniciado quando um inventário de plantas produtoras de resina através de períodos geológicos mostra que abundantes produções de resina parecem ter ocorrido primariamente em ambientes tropicais e subtropicais (Langenheim, 1969, 1973, 1975). Entretanto, a maioria das informações presentemente disponíveis, considerando variações em composição, tem vindo de estudos de gêneros comercialmente importantes em florestas de coniferas de regiôes temperadas. Por causa desta significante falha de conhecimento, a investigação de Hymenaea foi iniciada na tentativa de entender a significação do ambiente tropical na produção dessas grandes quantidades e diversidade de componentes por vários gêneros. O gênero Hymenaea, por diversas razões, é uma excelente unidade evolucionária para iniciar análises desta natureza. Primeiro, é membro da família Leguminosae, uma das maiores famílias de plantas produtoras de resina. Esta família tambéni retém alguns dos maiores e proeminentes componentes dus ecossistemas tropicais do Novo Mundo e África (Langenheim, 1973). Além disso, Hymenaea é a fonte de ambar (resina fóssil) de depósitos terciários no México, Colômbia e Brasil (Langenheim, 1964, 1966, 1969a) e um gênero anfiatlântico com sua provável origem na tloresta chuvosa da África no princípio do período ter-

(") - Division of Natural Sciences, University of California, Santa Cruz, CA 95064 USA 
ciário, com migração para o Novo Mundo e então subseqüente penetração em todos os principais ecossistemas de baixa altitude (Langenheim, 1973; Langenheim, Lee \& Martin, 1973; Lee \& Langenheim, 1975) .

A composição de resina e o sistema anatômico de secreção em Hymenaea difere em folhas, tecidos primário e secundário do caule e filtos (Langenheim, 1967, 1969a, 1973). Em muitas plantas (não Hymenaea), as resinas contêm voláteis mono- e sesquiterpenóides, bem como não voláteis di- e triterpenóides. Em Hymenaea, resinas em tecidos secundários do caule e frutos contêm primariamente di-terpenóides com alguns sesquiterpenos (Langenhoim, 1973, 1974; Lee \& Langenheim, 1975). As foilhes e tecidos primários do caule, entretanto, contêm somente hidrocarbonetos sesquiterpenos, os quais são secretados em pequenas bolsas (Langenheim, 1967; Martin, Langenheim \& Zavarin, 1972; Langenheim, Foster, Lincoln \& Stubblebine, 1977). No grande campo de estucic evolucionário, resinas desses diferontes órgãos estão sendo estudadas comparativamente.

Esiudos da variação intra e interspecifica de sesquiterpenos da folha, foram feitos iniclaimente utilizando-se plântulas de 35 populações de 11 espécies do gênero e desenvolviclas em estufa. Entre espécies de Hymeneva ou entre populações de certas espécies, diferenças quantitativas na composição da resina da fetha, são sobrepostas pela similaridade básica da qualidade de todos os membros do gênero. Em H. courbaril, a quaì ocupa todos os maiores ecossistemas tropicais de baixa elevação em seu largo domínio geográfíco, a variação em composição entre populações é quase tão grande quanto naquelas onze poculiares espécies estudadas.

O estudo do sistema de resina da folha tem vantagens por várias razões: 1) sua composição é relativamente simples, 2) torna-se possivel estudos sob condições experimentais, c 3) seria esperado que as plantas sob condiçōes naturais estejam sob forte pressão seletiva. Um estudo de 22 populações geográficas de $H$. courbaril tem mostrado que a variação na composiçẫo de resina da bolsa da folha dentro das populações locais da América Central é muito pequena, ao passo que a variação entre astas populações é muito maior (Martin, Langenheim \& Zavarin, 1974). Este fato contrasta com a composição da resina da foiha de várias populações de $H$. courbaril e outras espécies da América do Sul, onde a variação dentro de uma população local é algumas vezes muito maior do que entre muitas populações locais. Em verdade, a composição da resina geralmente é mais variável em populações da Amazônia e sul desta área onde a variação morfológica também é maior, do que na distribuição norte do gênero. No entanto, não há evidência para a aparente relação direta entre a diferenciaçãc de caracteres morfológicos e químicos.

Em estudos clonais de composição de resinas em coniferes de clima temperado, constatou-se que a variação nos genótipos era muitc mais baixa do que a variação entre genótipos, indicando que modificações ambientais na composição da resina nas ccníferas estudadas são limitadas. Em Hymenaea um estudo preliminar da plasticidade do fenótipo na composição da resina da folha - usando clones - indicou que extremas diferenças em fotoperiodismo, intensidade de luz e temperatura, têm pouco ou nenhum efeito sobre a composição. Um subseqüente $\in$ studc detalhado dos efeitos de extremas diferenças em fotoperiodismo sobre o crescimento vegetativo e composição de resina foliar em cincc populações de $H$. courbaril. confirmou este baixo grau de plasticidade do fenótipo em composição (Stubblebine, Langenheim \& Lincoln, 1975). Estes estudos sugerem que a variação na composição reflete diferenças no genótipo, não apresentando plasticidade fenotípica em resposta a fatores físicos do ambiente durante o crescimento das plantas.

Nos estudos iniciais da variação de ccmposição, três tịpos químicos foram caracterizados tendo em vista o nosso entendimento dos passos bioquímicos dos hidrocarbonetos sesquiterpenos (Martin, Langenheim e Zavarin, 1974, 1976b). Estes tipos puderam ser distinguidos baseados nas proporções relativas dos maiores componentes $\alpha+\beta$ selineno cariofileno, e a soma de y-muroleno e $\delta$-cadineno. O Tipo I foi caracterizado por um ccinteúdo de $\alpha+\beta$ selineno maior que $65 \%$ do total de sesquiterpenos, menos de $10 \%$ de cariofileno e muito pouco y-muroleno e \&-cadineno. O Tipo 
II tem uma composição constituída de um conteúdo moderamente alto de cariofiieno (usualmente $15-35 \%$ ) e y-muroleno e 8 -cadineno inversamente proporcional ao conteúdo de selineno, o qual nunca se torna maior que no Tipo I. O Tipo II é o modelo de composição mais comum em Hymenaea. O Tipo III difere do Tipo II, pois, embora acompanhando um baixo conteúdo de $\alpha+\beta$ selineno $(4-27 \%)$ não apresenta elevados valores de $y$-muroleno e cadineno como a inversa proporcionalidade do Tipo II requeriria. Em vez disso, há um conteúdo excepcionalmente alto (acima de $70 \%$ ) de cariofileno. Estes modelos de composição são suficientemente distintos, possuindo características próprias, ocorrendo usualmente um só tipo por população. Entretanto, em certas espécies ( $H$. parvifolia e $H$. aurea) ou populações de $H$. courbaril (v. courbaril ou v. stilbocarpa) dois ou três tipos devem ocorrer na progênie de uma única planta. Em subseqüentes estudos com outras populações e espécies, dois adicionais tipos (IV e V) têm sido observados, e no presente estudo um sexto tipo tem aparecido. O Tipo IV, o qual é caracterizado pelas altas proporções de $\beta$-copaeno (mais de $15 \%$ ). e de $\delta$-cadineno (mais de $25 \%$ ) e uma baixa percentagem de cariofileno (menos de $10 \%$ ), ocorreu na população de $H$. courbaril v. stilbocarpa de Itambé, Bahia, Brasil. O Tipo V tem sido notado em populações de $H$. parvifolia onde há predominância (usualmente mais de $60 \%$ ) de um composto presentemente desconhecido e que provavelmente não foi separado do $\alpha$ e $\beta$ selinenos em análises prévias de $H$. parvifolia. O Tipo VI é estreitamente relacionado com o Tipo I, apresentando percentagens relativamente elevadas de selinenos e baixas de cariofilenos, porém, é adicionalmente caracterizado por comparativamente alto copaeno e um desconhecido composto de pequeno tempo de retenção pelo Gás-Líquido-Cromatógrafo que aparece em numerosas espécies e populações de $H$. courbaril. Embora, haja uma aparente variação do Tipo 1, esta composição ainda parece ser suficientemente distinta para ser aqui reconhecida tentativamente como um tipo. Mais tarde, em estudos detalhados de populações da Amazôhíia, entretanto, ele será novamente analisado. Tipos I, III, IV e V têm pequena variação na quantidade dos componentes do diagnósti- co. Quanto mais um tipo ocorre em uma população, mais €le é, claramente distinto, não ocorrendo indivíduos intermediários. O Tipo II por outro lado, é altamente variável. Com o aparecimento desses últimos três modelos de variação, uma análise mais completa do con. ceito de tipos e sua classificação serão discutidos em outro trabalho (Langenheim, Stubblebine Foster \& Lincoln, 1977).

A existência de diferentes tipos de composição e grandes variações intra e interespecífica na composição da resina permitiu o exame de co-ocorrência quantitativa, usando métodos desenvolvidos por Zavarin (1970), de particulares componentes sob extremos iimites de composição, conduzindo a uma proposta de rotas biossintéticas alternadas de hidrocarbonetos sesquiterpenos. Desta forma, uma quantitativa proporcionalidade entre cariofileno e $\beta$-humuleno indicou que eles são provavelmente derivados ce um intermediário muito fechado em vez de via diferentes passos bioquímicos. Igualmente, §-cadineno parece mais proximamente relacionado biossinteticamente ao $y$-muroleno do que ao $y$-cadineno. A relação quantitativa encontrada em resinas de folha de Hymenaea entre $\alpha$-e $\beta$-selinenos, cariofileno e $y$-muroleno $\delta$-cadineno é difícil de explicar, entendendo-se os passos teóricos mais largamente aceitos, e por conseguinte, uma rota biossintética alternativa via germacrenos intermediários (Fig. 1) tem sido sugerida.

A existência desses modelos geneticamente controlados de variação química, deve ser devido tanto à variação genética do acaso como à variação genética sob pressão seletiva de várias condições ambientais. Considerável discussão tem sido produzida sobre o problema, se a variação do acaso ou a seleção natural controla a variabilidade em árvores tropicais (Ashton, 1969; Bawa, 1974). Corner primeiro sugeriu que árvores de floresta tropical úmida devem ser autopolinizadas porque elas florescem assincronicamente e, também, porque ele pensava que a movimentação de seus polinizadores devia ser limitada a pequenas distâncias. Federov (1966) apoiou fortemente esta opinião de que a efetiva população cruzada era tâo baixa em espécies da floresta tropical úmida (devido ao isolamento espacial resultan- 


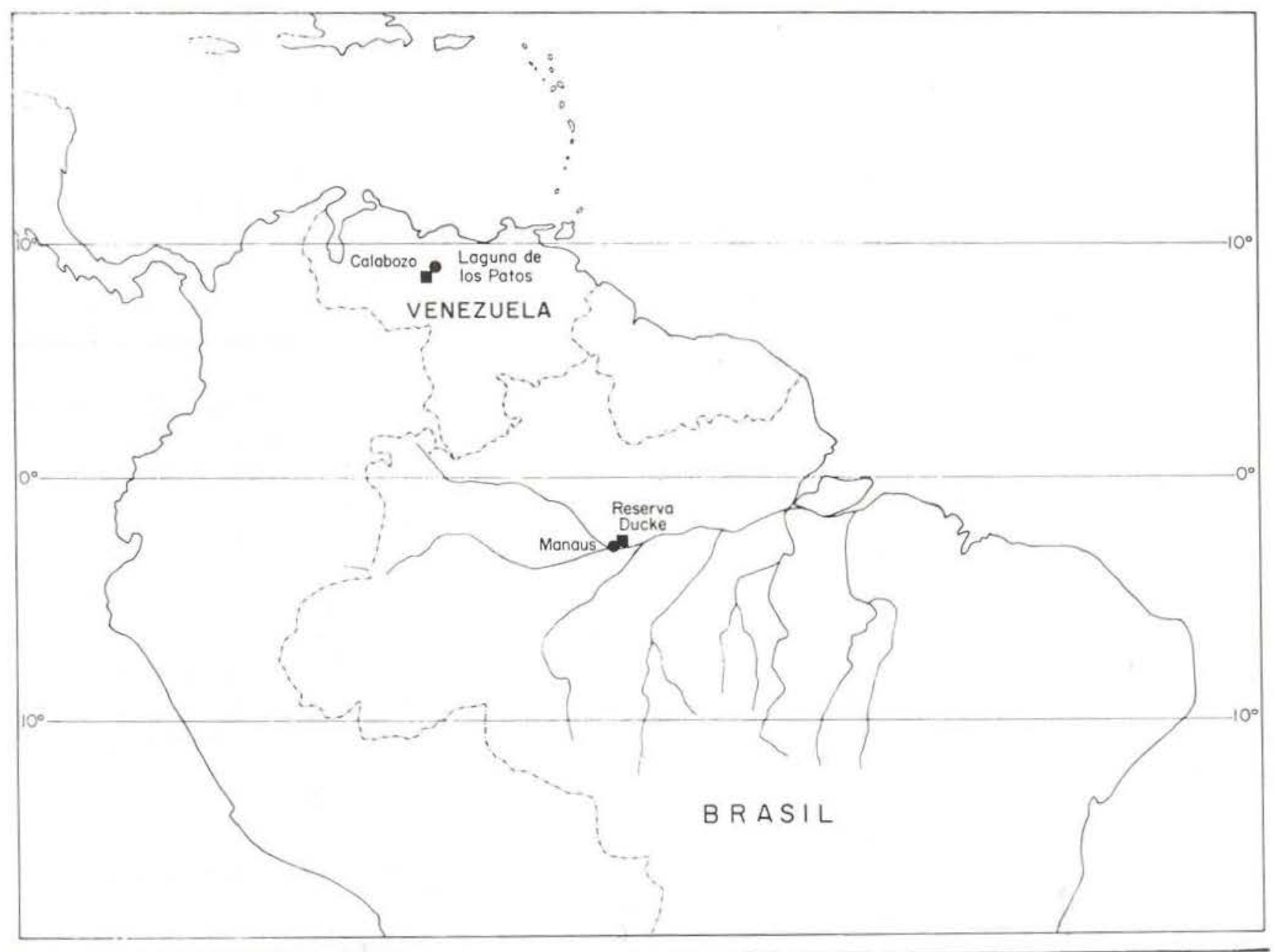

Fig. 1 - Localização dos pontos de coleta de exemplares de folha de Hymenaea.

te da baixa densidade de indivíduos de uma mesma espécie) que a autopolinização "devia ser a regra geral". Essa situação resultaria na dominância de "automáticos processos genéticos", tais como variação do acaso, sobre processos de seleção natural, conduzindo a uma rápida evolução através do aumento em heterozigosidade e, não adaptável diferenciação de pequenas populações. Um adicional aspecto do argumento dos proponentes deste ponto de vista é que há insuficientes diferenças no ambiente físico da floresta tropical úmida para prover operativas forças seletivas diferenciais, e, portanto, as espécies não são adaptadas dentro de específicos nichos. Ashton (1969) entretanto, aoha que fecundaçẩo cruzada está ocorrendo e mais ainda, concorda, com Dobzhansky (1950) que existem adaptações altamente especializadas ao ambiente físico (particular- mente edáfico) e ao extremamente complexo meio biológico. Em outras palavras, adaptações serăo direcionadas para maior integração com fatores edáficos e bióticos do meio ambiente. Ainda assim, Poore (1968) mostrou que um só aparente microhabitat deve ser preenchido por acaso por uma ou várias espécies alternativas. Quando há abertura natural de uma "falha" na floresta, plantas novas de uma determinada espécie podem por acaso estar exatamente no estágio certo para tomar seus lugares no dossel da floresta.

Janzen (1970) apresentou a idéia de que habitat em florestas tropicais úmidas, pode suportar mais espécies quando estes habitats tornam-se mais favoráveis para as sementes ou para os predadores de plântulas. Connell (1971) também está de acordo com este ponto, particularmente enfatizando a importância da 
predação em plântulas. Pressões de predador impediria uma dada espécie de tornar-se suficientemente abundante para competir com as outras. Entretanto, esta opinião pressupõe não somente uma alta diversidade mas, também, uma elevada proporção de herbívoros especializados, os quais não têm sido cuidadosamente documentados, por enquanto. Janzen aponta mais adiante que o desafic de predadores pode ser encontrado somente através de mudanças de comportamento ou mudanças químicas, as quais devem ser transmitidas geneticamente. Quanto mais favorável o meio físico para os predadores, mais freqüentemente (tempo evo(ucionário) as defesas químicas da planta terão de ser modificadas através de mudanças genéticas, isto é, se a planta tem sucesso na comunidade. Janzen adicionalmente sugere que estas circunstâncias ditam a importância de fecundação cruzada. O estudo de Bawa (1974) em uma lloresta semidecídua de terra bai$x a$, em Costa Rica, evidencia que as árvores sāo largamente de fecundaçāo cruzada. Bawa \& Opler (1974) neste mesmo tipo de floresta demonstraram que a grance maioria das espécies são dioicas e advogam que na maioria das espécies estudadas, dioicismo tem provavelmente evoluído de um sistema autocompatível de cruzamento para a fecundação cruzada em resposta à pressão seletiva. Também tem sido observado que o comportamento alimentar de algumas abelhas tropicais, morcegos e borboletas que voam a longa distância entre plantas, permite fecundação cruzada.

O sistema de recombinação de plantas superiores geralmente tem sido correlacionado em consideraçầo à competição, com vários fatores físicos do ambiente e, assim, com seus lugares em sucessão (i.e., pioneiras, climax, etc.). Levin (1975) acha que desafios produzidos por doenças e predação, devem freqüentemente ser mais significantes e mais "insidiosos" do que aqueles apresentados por fatores abióticos. Em vários graus, espécies são sujeitas a pressōes prognosticáveis, sistemáticas e direcionais de patógenos e herbívoros, participando com eles naquilo que tem sido chamado metaforicamente uma "evolutionary arms race" "(Feeny, 1976) ou uma "evolutionary dance" (Whittaker, 1969). Estes agentes de seleção favorecem o desenvolvimento de ati- tude defensiva sobre parte dos hospedeiros que por sua vez será balanceada pela contra adaptação do predador ou do parasita. Subseqüentes ciclos de adaptação e contra-adaptação alteram a posição dos participantes no "passo da dança" e faz com que as espécies hospedeiras sejam encaradas como em contínua mudança, o que significa distintos e heterogêneos desafıos na evolução do tempo. A soma de recom. binação dentro da área de ação de uma espécie deve ser relatada na geografia de predação e pressões patogênicas dentro daquela área, porém relações gerais entre a distribuição das duas não consiituem necessàriamente causa $\mathrm{e}$ efeito. Levin (1975) sugere que as maiores pressões de herbívoros e patógenos ocorrem em comunidades de longa existência, relativamente estáveis, especialmente comunidades tropicais em "climax", uma opinião apoiada também por Langenheim (1969b, 1975). No entanto, ainda não há evidência irrefutável substanciando esta opinião. É nos trópicos úmidos que o mais complexo aparato de interações de espécies entre nível trófico e suas relacionadas adaptaçōes e contra-adaptações encaradas e químicas seria esperado ocorrer. Levin (1975), Janzen (1973) e Grubb (1977) afirmaram que os maiores niveis de especificidade de hospedeiros por pequenos herbivoros e fungos, ocorrem com maior freqüência em baixas elevações dos ecossistemas tropicaıs do que nos temperados. Eles também indicam que uma maior fração da produtividade vegetal é colhida por herbivoros em florestas úmidas tropicais, do que nas temperadas - sendo maior a pressão herbívora causada por maior número de insetos e mamíferos explicitos na diversidade de espécies e geralmente na falta de flutuações de estações em populações herbivoras.

As floras tropicais parecem ser meihor dotadas de elementos químicos secundários que devem funcionar defensivamente, do que as florestas temperadas, como tem indicado as análises dos terpenóides de resinas feitas por Langenheim (1969b, 1975) e em estudos de Levin (1975) com alcalóides. A taxa pela qual a resistência química para herbívoros é realizada está na dependência de condições, tais como: relações de dominância e número de gens que controlam o caráter; aptidão relativa 
geral do tipo tolerante; tamanho da população de pragas, e taxa de disseminação de gens resistentes. Substituição cie gens em um ou poucos lóculos deve alterar o metabolismo secundário da planta, na forma em que ela se torna resistente a uma determinada peste. Onde os gens podem ser identificados por segregação Mendeliana, alelos para resistência têm sido encontrados como dominantes sobre aqueles para susceptibilidade. Por exemplo, dois gens principais controlam a síntese do gossipol, o qual produz resistência contra diversos herbívoros em algodão (Lee, 1965; Lee, Cockerhaun \& Smith, 1968). Resistência a doenças, usualmente, não é simplesmente herdada. Em alguns casos, entretanto, ela é controlada por um único gen - como no caso do cucurbitacin, - qual produz resistência do pepino a ácaros (Dacosta \& Jones, 1961; Koolstra, 1961).

Evidência da facilidade seletiva com que pestes se adaptam aos pesticidas indica que a defesa quimica da planta deve produzir somente uma pequena pausa dos efeitos de debilitação de pestes e patógenos. Janzen (1973) sugeriu que as pragas e doenças tropicais são superiores aos seus contrapartes de clima temperadio no desenvolvimento de resistência às substâncias quimicas. Ele atesta que a defesa das pragas e doenças contra os químicos das plantas é mais elaborada nos trópicos e a combinação da qual, espécies resistentes devem evoluir, é muito mais rica nos trópicos do que em comunidades temperadas. A habilidade dos herbivoros e patógenos em vencer as defesas das plantas pode ter efeitos catastróficos notável em agro-ecossistemas - e também em ecossistemas naturais da mesma forma. Em geral, doenças e desfolhamento causam mortalidade, menor produção de sementes e redução da habilidade interspecifica competitiva (Kulman, 1971; Rockwood, 1973).

A despeito deste potencial para devastação, existe uma controvérsia considerando a percentagem de folhas das plantas da floresta tropical úmida, que é consumida por animais antes que elas caiam ao solo. Fittkau \& Klinge (1973) atestam que na Amazônia Central as foihas representam somente $20 \%$ da biomassa viva; de somente suas observações gerais, eles indicam que as folhas são utilizadas por relati- vamente pequeno número de taxa e de indivíduos. Eles listam somente Orthoptera, Atta, Coleoptera, Hemiptera, Lepidoptera, preguiças, papagaios e primatas como herbívoros. Entretanto, outros apresentam números totalmente diferentes sobre esta controvérsia. Eidmann (1943) e Buchier apud Mann, 1968, relatam que cerca de $25 \%$ da matéria foliar é consumida no Oeste da África e América do Sul por herbivoros. Odum \& Ruiz-Reyes (1970) Estimaram que $7 \%$ da área foliar é consumida por animais em Porto Rico. E Cruz Acosta (1964) calculou 6\% em Costa Rica, baseando-se em uma amostragem muito pequena. Cruz Acosta concorda com o estudo de Bray em florestas temperadas, na qual a utilização de folhas por animais está correlacionada ao conteúdo nutritivo das folhas. Fittkau acha que encontrando baixo conteúdo de nutrientes na liteira de folhas da Amazônia Central (Klinge \& Rodriges, 1968) apoia a opinião de que baixas quantidades de materia foliar entram na corrente de alimentação. Por outro lado, nossas observações gerais na Reserva Ducke indicam considerável ataque de herbivoros na vegetaçāo de baixo crescimento.

Feeny (1976) chama atenção do prevalecimento da ignorância da importância relativa de pressões seletivas de diferentes classes taxonômicas de herbívoros e patógenos na evolução de defesas químicas pelas plantas, isto é, tem sido dada demasiada ênfase sobre o papel áos insetos. Enquanto o papel das plantas em moldar contra-adaptações químicas para insetos é freqüentemente clara, os efeitos dos insetos na evolução da defesa da planta devem ser vistos em um mais largo contexto coevolucionário. Defesas químicas da maioria das espécies vegetais sofrem coevolução com uma variedade de predadores, parasitas e competidores. Espécies de plantas (ou ao menos populações) são consideradas como "ilhas" quimicamente defendidas, sujeitas a colonização por populações e espécies de pestes no tempo evolucionário.

Pesquisas relativamente recentes sobre várias associaçōes planta-herbivoro são conduzidas à conclusão de que defesas químicas de plantas podem ter efeitos de mais longo alcance em comunidades naturais, do que as inicialmente comentedas neste trabalho (Feeny, 
1976; Rhoades \& Cates, 1976). Hipóteses têm sido lançadas acerca de como defesas químicas das plantas contra herbívoros e patógenos podem variar como uma função de persistência e abundância de planta, e, cumo, por sua vez, tais variações devem ser esperadas afetar a ecologia dos herbívoros e suas plantas/alimento em diferentes comunidades vegetais.

A diversidade de tipos químicos entre plântulas originárias de sementes de uma única árvore mãe tem nos levado a comparar tipos de composição entre árvores parentais e suas progênies em diferentes ecossistemas. Pelos nossos prévios e limitados dados parece que os modelos da diversidade na composição da resina devem estar relacionados a pressões seletivas de predadores e patógenos. O presente trabalho é o primeiro de uma série na qual faremos comparações de árvores parentais e suas progênies de espécies amazônicas de Hymenaea $(H$. intermedia e $H$. parvifolia) com $H$. courbaril nos Llanos da Venezuela. Subseqüentemente, faremos comparações de adicionais espécies amazônicas $H$. reticulata e $H$. courbaril v. subsessilis) com outras espécies de Hymenaea ( $H$. stigonocarpa) e outras variedades de $H$. courbaril (v. stilbocarpa) do cerrado e de florestas úmidas do sul do Brasil.

\section{DESCRIÇÃO DAS ESPÉCIES DE HYMENAEA}

\section{ESTUDADAS E SEUS LOCAIS DE COLETA}

Objetivando análises químicas exemplares de três espécies de Hymenaea ( $H$. intermedia, $H$. parvifolia, e H. courbaril) foram coletadas em duas localidades distintas. A primeira foi a Reserva Florestal Ducke, localizada no Município de Manaus, Amazonas, Brasil; e a segunda foi uma área adjacente a Estacion Biologica de Los Llanos próximo a Calabozo, Guarico, Venezuela (Figura 1).

A Reserva Ducke compreende uma área de $100 \mathrm{~km}^{2}(10 \mathrm{~km} \times 10 \mathrm{~km})$ coberta com vegetação primária e secundária (em alguns locais) de floresta tropical de terra firme. Foi realizado um inventário florístico de um hectare com a finalidade de analisar a possibilidade de utilização de madeira naquele tipo de floresta (Lechthaler, 1956). Setecentas e trinta e cinco árvores individuais foram encontradas, perten- cendo predominantemente às famílias Lecithydaceae a Leguminosae (Cesalpinioideae), porém espécies de Hymenaea não ocorreram dentro das parcelas estudadas. Entretanto, quatro indivíduos de $\mathrm{H}$. intermedia e um de $\mathrm{H}$. parvifolia foram incluídos nos estudos fenológicos os quais foram iniciados em 1962 (Araujo, 1970). Estes cinco indivíduos ocorrem mais ou menos em linha paralela à estrada de acesso da qual dista cerca de $500 \mathrm{~m}$, em solos ferralíticos (Ultisol ou Oxisol). Essas duas espécies têm ocorrido também na Reserva Egler ao longo da estrada Manaus-Itacoatiara, muito embora elas não tenham sido encontradas nas parcelas amostradas por Rodrigues (1967).

A ocorrência de cinco indivíduos em uma distância linear de $500 \mathrm{~m}$ foi uma sorte para os nosses estudos. Pouco se conhece em relaçăo à freqüência e densidade dessas espécies na Amazônia. Os únicos estudos quantitativos que incluiram espécies de Hymenaea são aqueles de floresta de terra firme realizado a $42 \mathrm{~km}$ $\mathrm{N}$-NE de Manaus no qual H. courbaril (provavelmente var. subsessilis) foi encontrada no estrato B (Takeuchi, 1961) e duas de quatro parcelas próximas de Belém e estudadas por Black, Dobzhansky \& Pavan (1950), e Pires, Dobzhansky \& Black (1953). Dois indivíduos de espécies desconhecidas de Hymenaea estiveram presentes em 3.5 hectares de terra firme, área a $120 \mathrm{~km}$ de Belém (Três de Outubro), porém Hymenaea não foi encontrada em um hectare de terra firme próximo de Belém. Black, Dobzhansky \& Pavan entretanto, indicaram que eles não tinham registrado mais do que a metade das espécies na comunidade que eles tinham analisado na parcela de um hectare e que a maioria das raras e, mesmo das espécies mais ou menos comuns, foi perdida nas suas parcelas. Ademais, o tamanho da parcela de Belém provavelmente explica a ausência de Hymenaea em uma área onde ela é conhecida ser realmente comum (como no caso de ambas reservas Ducke e Egler). Por outro lado, três indivíduos de Hymenaea ocorreram em um hectare ao longo do rio Guamá, perto de Belém. Três individuos por espécie foi o número máximo achado nas parcelas de um hectare. De fato, um terço das espécies que ocorrem em parcelas de um hectare foram representados por um único indivíduo. Dois dos indivíduos 
foram identificados como $H$. parvifolia e o terceiro não foi identificado. Nós suspeitamos de erro na identificação de $H$. parvifolia porque em nossa experiência ela não ocorre em igapó e sim em ambiente de terra firme. Em vez disso, esperariamos $H$. oblongifolia em floresta de igapó. Considerável variabilidade morfológica caracteriza populações de $H$. parvifolia, uma variabilidade também refletida na composição da resina da folha. Na Amazônia, Hymenaea parvifolia ocorre com maior freqüência em campos e áreas de savana, do que outras espécies de Hymenaea. Quanto à forma, varia de arbusto no centro do campo para árvore emergente na adjacência da floresta chuvosa.

Plantas de florestas não chuvosas tendem caracterizar a maioria dos campos; no entanto. H. parvifolia ocorre em ambos ambientes. De fato, é na área de contato campo-savana e floresta chuvosa que $H$. parvifolia mostra sua grande variabilidade. Nas Reservas Florestais Ducke e Egler, H. parvifolia ocorre misturada com $H$. intermedia e ela é uma árvore emergente (ca. $35 \mathrm{~m}$ de altura) com um diâmetro de cerca de $49 \mathrm{~cm}$. Plantas novas ocorrem sob a árvore, porém esparsamente.

Hymenaea intermedia é morfologicamente intermediária entre $\mathrm{H}$. oblongifolia e $\mathrm{H}$. courbaril. Ela geralmente ocorre em terra firme em relativamente restritas áreas das partes mais secas do centro e leste da Amazônia. Ecologicamente $H$. intermedia está mais próxima a $H$. courbaril do que $H$. oblongifolia, e, tem sido sugerido que $H$. intermedia representa uma estirpe proximamente relacionada a $\mathrm{H}$. oblongifolia de cuja plástica fisiológica $H$. courbaril poderia ter evoluído (Lee \& Langenheim, 1975). Hymenaea intermedia é a mais comum das três espécies que ocorrem na Reserva Ducke. Ela é uma árvore emergente variando de 27-39 metros de altura com um diâmetro médio de $48 \mathrm{~cm}$. Plântulas são abundantes sob a árvore com a maior concentração, freqüentemente, nas bordas da copa.

Hymenaea courbaril var. subsessilis é relativamente comum em solos arenosos na área de Manaus, em alguns casos sendo observada em agrupamentos de 4 ou 5 árvores. Ela ocorre em qualquer lugar da Amazônia em areia de praia ao longo dos tributários do rio Amazonas.
H. reticulata presentemente é conhecida somente através de umas poucas árvores que ocorrem na Reserva Ducke. Ambas $H$. courbaril var. subsessilis e $H$. reticulata serão analisadas em estudos subseqüentes.

A Estación Biológica de Los Llanos, operada sob os auspícios da Sociedade Venezuelana de Ciências Naturais possui 250 hectares de área no centro de Llanos Altos, perto de Calabozo, Guarico, Venezuela. Hymenaea courbaril var. courbaril é um compcnente comum da vegetação decídua, semidecídua e de savana na Venezuela. Hymenaea courbaril var. courbaril é menos comum na Bacia Amazônica, onde ela parece ser relativamente restrita aos locais de terra firme na zona leste da região, no norte da América do Sul e na América Central, onde ela é comum na maioria dos ecossistemas de baixa elevação e pode mesmo aicançar dominância em certos ecossistemas de florestas secas. Ela ocorre no sul da Bacia Amazônica, mas năo é tão abundante como no norte da Amazônia .

Hymenaea courbaril var. courbaril é uma árvore relativamente comum nas imediações da Estación de Biologia de Los Llanos. Para estes estudos ela foi amostrada no Lago de Los Paios. É uma árvore relativamente pouco alta (9-15 m de altura) o que é típico de sua ocorrência em savanas ou locais de floresta decídua. Com freqüência encontra-se em próxima associação com Copaifera pubiflora.

\section{MATERIAIS E MÉTODOS}

Amostras de foilha de três espécies $(H$. intermedia, $H$. parvifolia e $H$. courbaril) foram coletadas para análise usando-se o gás líquido cromatógrafo $(G L C)$. A coleta foi feita nas duas localidades anteriormente comentadas, bom como em plantas novas desenvolvidas em estufa da U. C. S. C.. O número de plântulas imediatamente disponivel sob ou perto da "árvore mãe" variou de 3 a 25 . A idade dessas jovens plantas coletadas no campo é desconhecida, conhecendo-se entretanto a idade dos exemplares crescidos em estufa. Em nenhum caso as mudas eram apenas germinadas (isto é, contendo ainda cotilédones e primeiras folhas). Os exemplares coletados na Reservá Ducke têm cerca de três anos de 
idade, pois, a última frutificação antes de nossa coleta em 1976, foi em 1973 (Tabela 2). Na verdade, em um caso ( $n$. 124) a última frutificação foi em 1972 e não foram encontradas plântulas sob esta árvore em 1976. No entanto, deve ser salientado que numerosas mudas foram coletadas nestas árvores durante o período maio/junho ds 1974 por membros do Curso de Eotânica do INPA em Ecologia Química. Nenhuma das mudas da Reserva Ducke apresentava suficiente desenvoltura para ser considerada plântula desenvolvida (sapling); todavia, sementes de $H$. parvifolia da Reservé Ducke haviam sido plantadas em nossa estufa na U. C S. C., variando de 6 a 10 anos atrás e apresentavam tamanho suficiente para serem consideradas plântulas desenvolvidas (saplings). Para firis de análise, essas plantas foram consideradas como um grupo único por causa de suas intermediárias e dos seus crescimentos em estufa. As populações de H. courbaril, em Llanos. tinham 25 exemplares sob uma árvore $e \mathrm{com}$ suficientes alturas para serem consideradas plântulas desenvolvidas, porém. nós não fazemos idéia sobre suas idades.

Embora comparaçães da composição química das resinas de folha de árvores parentais e de suas progênies fossem a finalidade primária deste estudo, diversas amostras de fotha de diferentes galhos de cada árvore mãe na Reserva Ducke foram coletadas a fim de observar a variação na composição da resina da folha de árvores aduitas. Nós antevemos pouca variação em árvores adultas porque isto tinha sido verificado em um grande número de plântulas, e plântulas desenvolvidas previamente estudadas na estufa. isto foi adicionalmente apoiado por estudos em ambiente controlado os quais indicaram que extremos de fotoperiodismo e cutros fatores físicos tinham insignificante influência na composição da resina.

As folhas foram secas ao ar e a composição da resina foi analisada utilizando-se uma folha madura. Estas amostras foram maceradas com um mortar, pilãa e areia, e a extração foi feita com n-penteno de elevada pureza, filtrada em papel de fiitro Whatman $n .^{\circ} 1$ e concentrâda por evaporação do solvente com uma suave corrente de nitrogênio. A solução resultante foi analisada diretamente pelo GLC (3\% Carbowax em gás-Chrom Q, $8 \mathrm{~m} \times 3 \mathrm{~mm}$, FID, integrador electrônico). Todas as computacões esiatísticas foram teitas em computadores PDP-45 e IBM 360 na Universidade da California, Santa Cruz.

\section{Resultados}

VARIAÇÃO EM ÁRVORES FARENTAIS

Análise de cincc amostras de cada uma das quatro árvores mãe de $H$. intermedia e uma de $H$. parvifolia substancia claramente que há pequenissima variação na composição da resina da folha de uma árvore individual (Figuras 2 e 3).

\section{VARIAÇÃo DA ÁRVORE MÃE EM RELAÇÃO} A PROGÊNIE

Nas popuiações de $H$. intermedia e $H$. parvifolia da Reserva Ducke, três tipos foram representados entre os adultos: $H$. intermedia com ambos, tipo III (2) e Tipo II (3) e H. parvifolia com Tipo 1 . Foi também digno de nota o aproveitamento de apenas um tipo na progênie (variando em número de 3-10) sob cada árvore mãe. Houve um aparente relacionamento entre árvores mäe de $H$. intermedia e plântulas sobreviventes. Uma árvore de folhas Tipo III tinha plântulas Tipo VI e, enquanto que duas árvorcs mãe do Tipo II possuiam plântulas do Tipo I a outra árvore Tipo II tinha mudas Tipo VI. Pode-se notar, entretanio, que o Tipo VI está proximamente relacionado ao Tipo I. A árvore mãe de $H$. parvifolia era dotada de folhas com resina cie composição Tipo I e as mudas sobreviventes tinham Tipo V. Contudo, talvez seja significante o fato de que plântulas desenvolvidas de $H$. parvifolia originárias de sementes coletadas em uma só árvore da Reserva Ducke e crescidas em estufa mostraram três Tipos I, II $\odot \mathrm{V}$.

Um previsto modelo menos variável ocorreu na população de $H$. courbaril originária da Venezuela. Igualmente, ambas as árvores parentais tiveram composição Tipo II, embora uma delas fosse excepcionalmente rica em cariofileno. As seis outras árvores adultas possuiam 

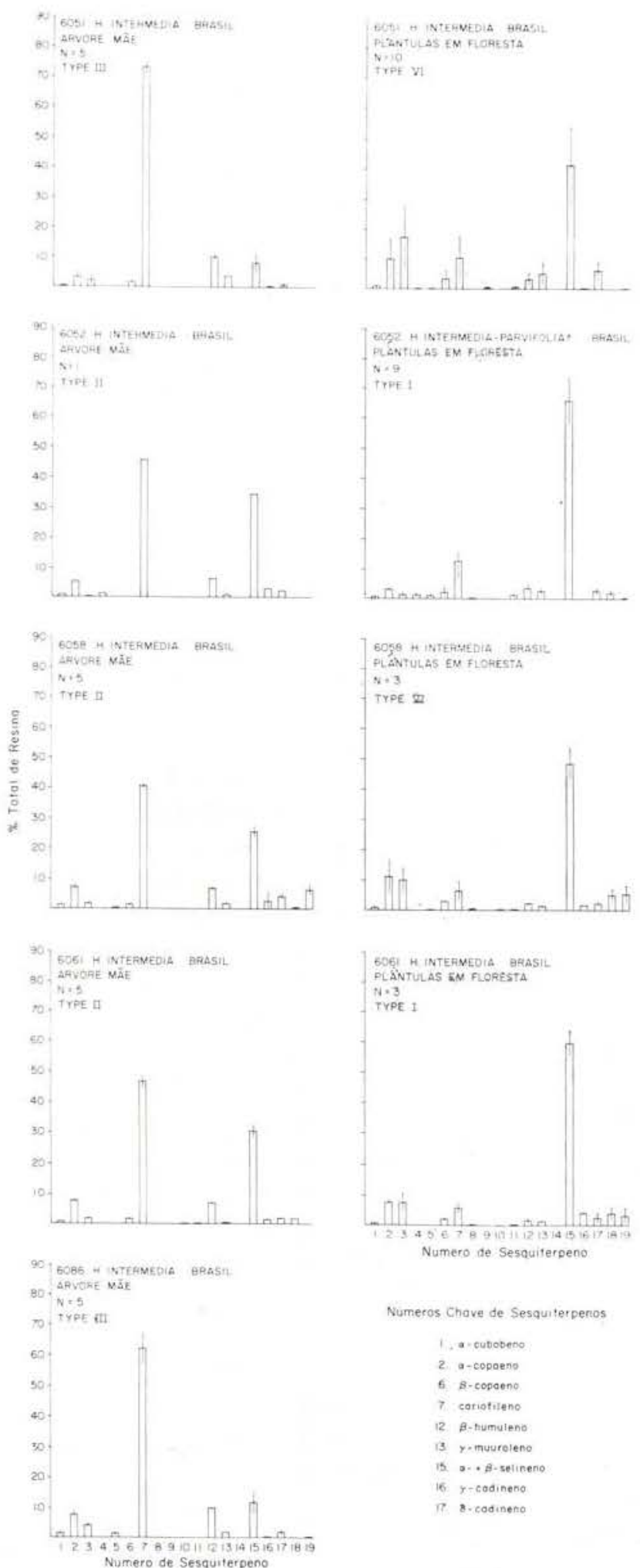

Fig. 2 - Histogramas mostrando tipos de composição de folhas de árvores adultas e plântulas de Hymenaea intermedia da Reserva Ducke, Manaus, Amazonas, Brasil.
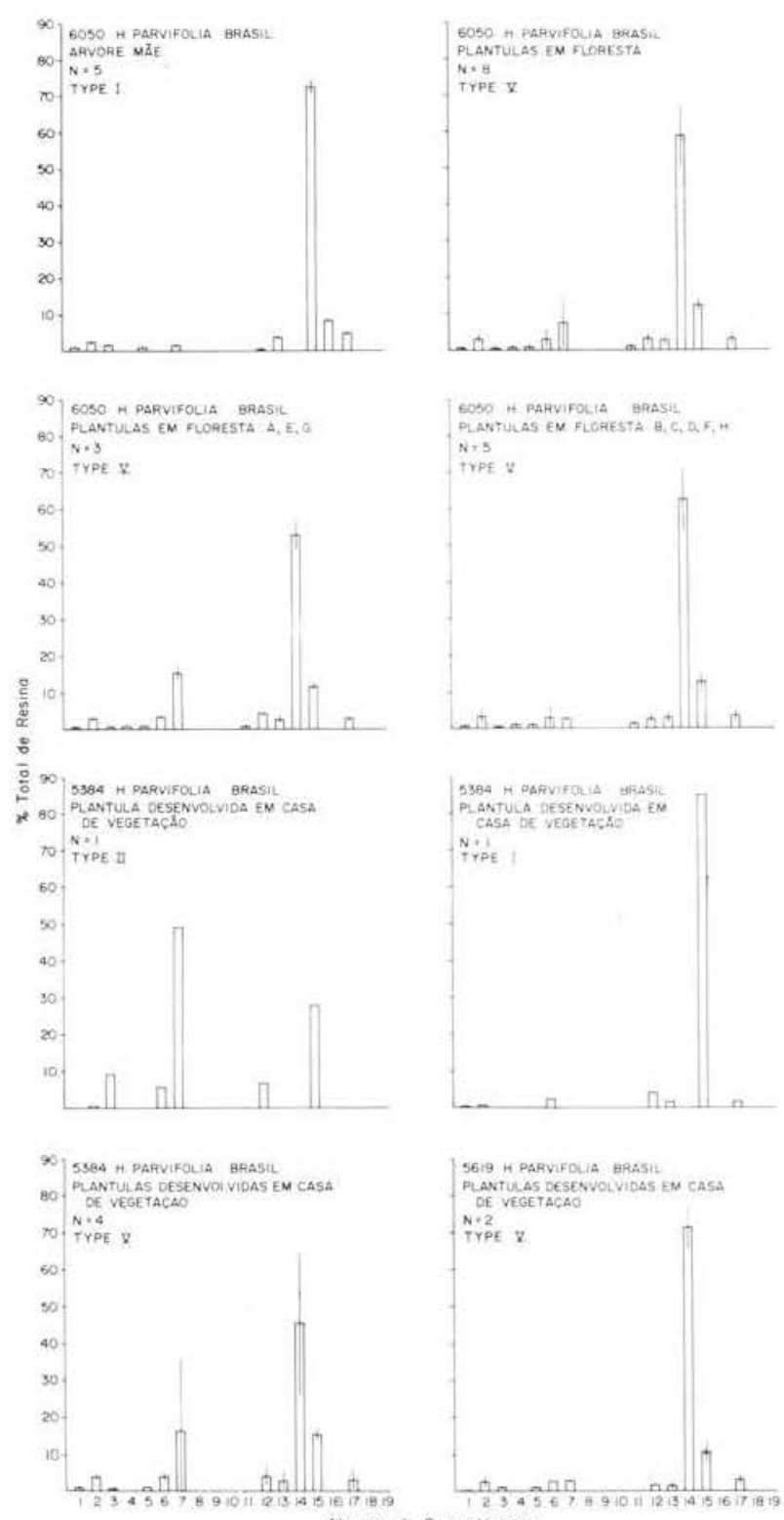

Fig. 3 - Histogramas mostrando tipos de folhas de árvores adultas, plântulas nativas e crescidas em estufa e plântulas desenvolvidas de Hymenaea parvifolia da Reserva Ducke, Manaus, Amazonas, Brasil.

composição típica do Tipo II com menos cariofileno e relativamente mais selineno (Tabeia I, Fig. 4). Todas as 14 "plàntulas" e 24 "plântulas desenvolvidas" sob a árvore mãe Tipo II tinham também composição Tipo II. Adicionalmente todas as 25 plântulas da outra árvore mãe foram claramente classificadas no Tipo II. Esta predominância da composição Tipo II em plantas novas em geral concorda com as aná- 
TABELA 1 - Espécie, localidade, número de coleta e representaçâo de tipos entre espécimes de árvore adulta, plân. tula e plântula desenvolvida. Os números da Reserva Ducke correspondem às árvores sob estudos fenoiógicos, $\left({ }^{\circ}\right)$ piântulas crescidas em estufa

\begin{tabular}{|c|c|c|c|c|c|}
\hline \multirow[t]{2}{*}{ Espécies } & \multirow[t]{2}{*}{ Localidade } & \multirow[t]{2}{*}{ Número de Coleta } & \multicolumn{3}{|c|}{ Número de Plantas e de Tipos Quimicos } \\
\hline & & & Adulto & Plantula & Planta desenvolvida \\
\hline H. intermedia & Reserva Ducke, 398 & JHL 6051 & $1(I I I) 5$ & $10(\mathrm{VI})$ & \\
\hline H. intermedia & Reserva Ducke, 124 & JHL 6086 & $1(I I I) 5$ & & \\
\hline H. intermedia & $\begin{array}{l}\text { Reserva Ducke, } 89 \\
\text { Amazonas, Brasil }\end{array}$ & JHL 6058 & $1(\mathrm{II}) 5$ & $3(V I)$ & \\
\hline H. intermedia & Reserva Ducke, 135 & JHL 6061 & $1(I I) 5$ & $3(1)$ & \\
\hline $\begin{array}{l}\text { H. interme cia } \\
\text { (adult) }\end{array}$ & & & & & \\
\hline $\begin{array}{l}\text { H. parvifolia (?) } \\
\text { (seedling) }\end{array}$ & $\begin{array}{l}\text { Reserva Ducke, } \\
\text { near } 170\end{array}$ & JHL 6052 & $1(I I)$ & $9(1)$ & \\
\hline H. parvifolia & Reserva Ducke, 393 & $\mathrm{JHL} 6050$ & $1(1) 5$ & $8(V)$ & \\
\hline H. parvifolia & Reserva Ducke, 393 & JHL 5384 & & & $\cdot 1(\mathrm{II}), \cdot 1(\mathrm{I}), \cdot 4(\mathrm{~V})$ \\
\hline H. parvifolia & Reserva Ducke & JHL 5619 & & & $2(\mathrm{~V})$ \\
\hline H. courbaril & $\begin{array}{l}\text { Laguna de los Patos } \\
\text { Guarico, Venezuela }\end{array}$ & JHL 6083 & $1(11)$ & $25(I I)$ & \\
\hline H. courbaril & Laguna de los Patos & JHL 6084 & $1(I I)$ & $14(11)$ & $24(I I)$ \\
\hline H. courbaril & Laguna de los Patos & $\begin{array}{l}\text { JHL } 6161,6162,6164, \\
6165,6167,6168\end{array}$ & $6(I I)$ & & \\
\hline
\end{tabular}

TABELA 2 - Anos de frutificaçăo de indivíduos de Hymenaea no estudo fenológico da Reserva Ducke. Todas as plantas sảo $\mathrm{H}$. intermedia exceto a 135, a qual é $\mathrm{H}$. parvifolia. $\mathrm{X}=$ frutos abundantes; $\mathrm{x}=$ poucos frutos.

\begin{tabular}{|c|c|c|c|c|c|c|c|c|c|c|c|c|}
\hline \multirow{2}{*}{$\begin{array}{l}\text { Arvore } \\
\text { número }\end{array}$} & \multicolumn{12}{|c|}{ Anos de Frutificação } \\
\hline & 65 & 66 & 67 & 68 & 69 & 70 & 71 & 72 & 773 & 74 & 75 & 76 \\
\hline 89 & $x$ & & $\mathrm{x}$ & & $\mathrm{x}$ & & $\mathrm{x}$ & $\mathrm{x}$ & $x$ & & & $\mathrm{x}$ \\
\hline 124 & $\mathrm{X}$ & & $\mathrm{x}$ & & $\mathrm{x}$ & & $\mathrm{x}$ & & & & $x$ & \\
\hline 135 & $x$ & & $\mathrm{x}$ & & $x$ & & $\mathrm{x}$ & & $\mathrm{x}$ & & & $\mathrm{x}$ \\
\hline 393 & & & & & & & & & $x$ & & $\mathrm{x}$ & \\
\hline 398 & & & & & & & $\mathrm{x}$ & & $x$ & & & \\
\hline
\end{tabular}




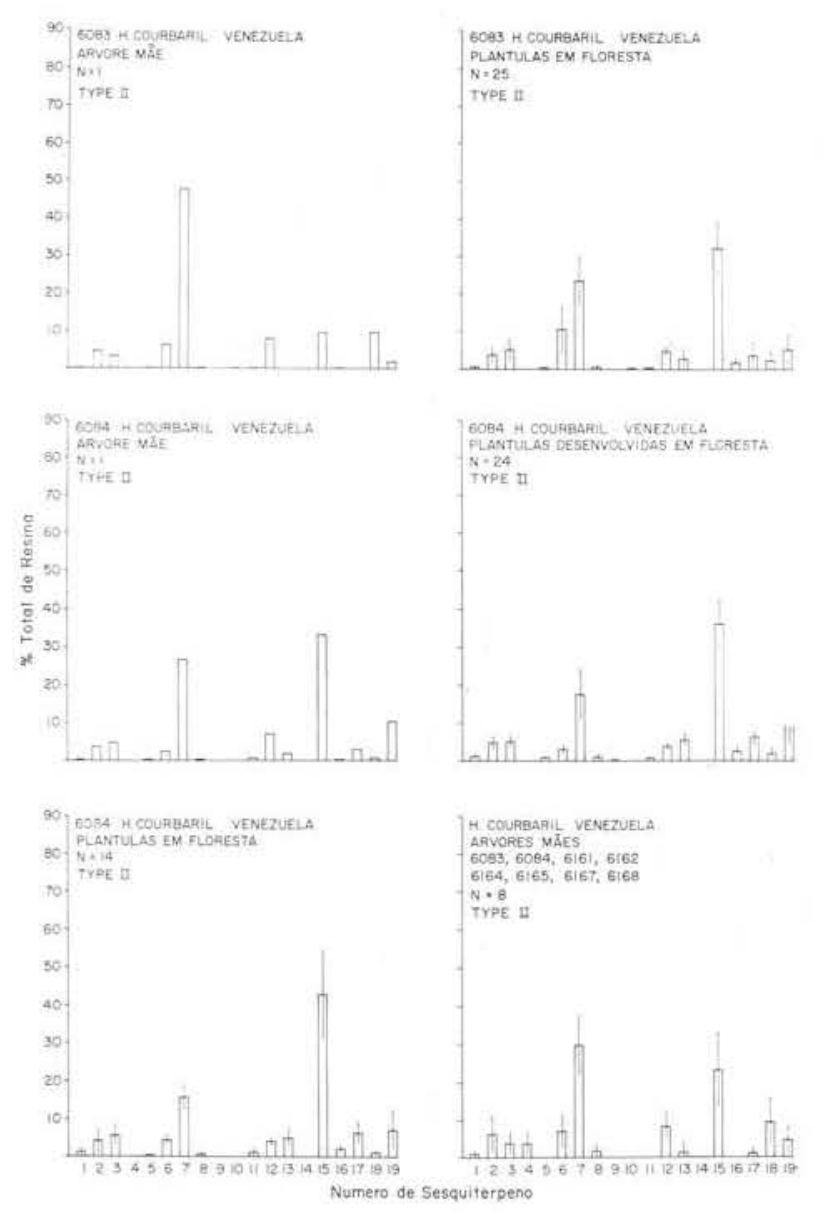

Fig. 4 - Histogramas mostrando tipo de composição de folnas de árvores adultas, plântulas e plântulas desenvolvidas nativas de Hymenaea courbaril da Laguna de Los Patos, Guarico, Venezuela.

lises prévias de mudas formadas em casa de vegetação cujas sementes foram originárias do Miéxico, Honduras, Costa Rica, Panamá e Venezuela (Martin, Langenheim \& Zavarin, 1974, 1976b) .

\section{ConcLusões}

Apesar do pequeno tamanho da amostra utilizada na maioria dos casos, neste presente estudo, as persistentes diferenças na composição química da resina da folha entre árvores parentais e suas progênies, bem como a maior variabilidade das populações de espécies da Amazônią Central, no Brasil, do que daqueias no centro des Llanos na Venezuela, conduzem a colocação de várias questões e sugestōes de hipóteses a serem testadas.
Primeiramente, deve-se indagar se as modificações na composição da resina das folhas mudam com a ontogenia da árvore, isto é, é diferente a composição da resina das folhas em plântulas, plântulas desenvolvidas e árvores aduitas em diferentes estágios de desenvolvimento? É sabido que mudanças quantitativas na composição química da resina têm lugar no desenvolvimento da folha (Langenheim, Foster, Lincoln \& Stubblebine, 1977). Por exemplo, em uma folha que tem típica composição Tipo II, teores de selineno são elevados nos primeiros cstágios de desenvolvimento aumentando a percentagem de cariofileno com o crescimento da folha. Em H. intermedia, cariofileno é particularmente notável na composição da árvore adulta. Duas árvores adultas têm composição Tịo III - isto é, com mais de $60 \%$ de cariofileno. Igualmente as composiçōes do Tịco II são mais altas em cariofileno do que o usual nestas populações (Figura 2). Cariofileno é também anormalmente elevado em amostras de uma das árvores adultas de $H$. courbaril na Venezuela (Fig. 4). Estes dados devem levar à conclusāo de que plantas novas poderiam apresentar um tipo de composição, e, progressivamente sofreriam mudança para um outro Łipo na árvore adulta. Por outro lado, em amostras da segunda árvore adulta de $H$. courbaril na Venezuela, selineno foi consistentemente mais alto, bem como na progênie de plântulas e árvores novas (embora a proporção de selineno e cariofileno fosse intermediária). não podiendo ser considerado Tipo II. Também, as seis outras árvores adultas amostradas são tipicamente de composição Tipo II. Esta predominância de composição Tipo II em piântulas nativas concorda com análises anteriores de plântulas crescidas em estufa, porém com sementes originárias de várias populações de $H$. courbaril da América Central e Améiica do Sul. De fato, o Tipo II é, o mais comum em todas as espécies. Igualmente, a árvore adulta de $H$. parvifolia teve composição Tipo I e todas as oito plântulas foram do Tipo $\checkmark$ (Figura 3). Todavia, duas plântulas da estufa apresentaram Tipo V, e cinco plântulas desenvolvidas apresentaram-se entre três tipos. Estas plântulas desenvolvidas também foram originárias de sementes coletadas em uma mesma árvore, variando de seis a dez 
anos passados, sob a qual todas as plântulas natives foram do Tipo $V$. Esta situação parece sugerir uma hipótese alternativa, embora não haja meios para provar, que a composição da resiná em folhas de uma árvore individual não muda progressivamente com as variaçōes ontogenéticas na maturação da árvore, sem verificar as mudanças ocorridas no período de muitos anos.

A comparação química da resina de foihas de plântulas sobreviventes em populações nativas sob a árvore mãe com aquelas "plântulas desenvolvidas" oriundas de sementes da mesma árvore e crescidas em estufa, conduz a colocação de uma outra questão. É claro que algumas árvores têm potencial genético para apresentar em seus microambientes progênies com vários tipos de composição e por conseguinte, pode ser que a seleção resulte na sobrevivência da plântula com folhas de um tipo diferente da árvore mãe sob a qual ela ocorre. Em H. parvifolia existe evidência que possivelmente apoia esse ponto de vista. Sementes da árvere $n .^{\circ} 393$ mostram três diferentes tipos quando crescidas no ambiente protegido da estufa, ao passo que somente o tipo $V$ parece ter sobrevivido na natureza. Todas as plântulas coletadas na Reserva Ducke tinham no mínimo três anos de idade, pois as árvores não tinham frutificado até 1973 (Tabela 2). Assim, pressões do potencial seletivo atuaram por um período relativamente longo, embora a seleção das plântulas tenha ocorrido abruptamente. As sementes são pesadamente consumidas por besouros (Scolitydae), gorguIhos (Rhinochenus) e uma larva de lepidóptero. Janzen $(1969,1970,1971)$ têm mostrado que H. courbaril, em floresta de estação seca, na Costa Rica, possui em áreas densas modelo reprodutivo diferente do verificado em ambientes abertos. Em situação de floresta densa, a árvore frutifica somente em cada 3 a 5 anos, ao passo que, em locais abertos ela frutifica $\mathrm{em}$ anos consecutivos. Ele sugere que a significante adaptação de dormência sexual está reduzindo fortemente a predação de sementes pelos gorgulhos do gênero Rhinochinus. Este comportamento da árvore significa para o gorgulho que as sementes são de três a cinco vezes tão escassas como seria indicado pela total densidade das árvores aduiltas. Também, onde este curculionídeo é ausente (norte de El Salvador até o sul do México e em Porto Rico), a árvore frutifica normalmente todos os anos. Todas as indicações são de que $H$. parvifolia e $H$. intermedia na densa floresta da Reserva Ducke estão tendo uma forma similar de predação com ciclo de frutificação ocorrendo de dois a três anos. O modelo de frutificação de $H$. courbaril não é conhecido no Llanos, porém suspeita-se que nestes locais abertos ela frutifique anualmente. Janzen (1970) além disso, sugeriu que a dispersão de sementes em locais próximos dos pais é afetada por dois diferentes grupos de predadores sobre as plantas jovens - predadores sensíveis à distância e sensíveis à densidade. A probabilidade de uma planta jovem ser atacada por um predador sensivel à distância é, primeiramente, uma funçāo da distância entre árvores jovens e aduitas da mesma espécie. Predadores sensíveis à distância são comumente parasitas de árvores adultás, porém predadores de plântulas. Isto é devido ao fato de que as piântulas não resistem à perda de folhas e brotos terminais no mesmo grau das árvores adultas. Por outro lado, a probabilidade de uma planta jovem ser atacada por um predador sensivel à densidade é primeiramente uma função da relação de densidade entre os jovens.

Assim, Janzen indica que qualquer estratégia que capacite uma árvore tropical a dispersar suas sementes de seus pais, e provavelmente contribuirá para assegurar o sucesso da progênie. Ele usa o exemplo da leguminosa trepadeira Dioclea megacarpa para mostrar quanto efetivo pode ser um predador sensivel à distância. Essa trepadeira hospeda uma grande população da larva "erebine noctuid" aparentemente hospedeira especifica, que come os brotos terminais da planta. A larva consome cerca de $50 \%$ das extremidades dos galhos novos, sendo observado uma "chuva leve" destas lagartas sobre o piso da floresta. Embora a maioria das larvas retorne para as copas, as restantes irão comer alguma intacta extremidade do brotc de uma plântula de $D$. megacarpa, que por sua vez, tem baixa reserva para ofere. cer a esse tipo de herbívcro. Por conseguinte, não existem sobreviventes de plântulas diretamente sob os pais, mas, plântulas com distância de mais que cinco metros da borca da copa 
da árvore mãe que mostram somente uma leve avaria causada por essas larvas. Janzen ainda indica que rodentes devem usar a árvore mãe como "bandeiras" indicando a presença de plantas jovens e, portanto, funcionando também como predadores sensíveis à distância. Adicionalmente, fungos hospedeiros específicos com esporos resistentes devem também servir como predadores sensiveis à distância ou patógenos letais. Em verdade, mesmo fungos sem esporos resistentes devem operar desta forma, se remariescentes das plântulas atacadas persistem de ano para ano. Desse modo, predadores sensiveis à distância podem ser muito efetivos em produzirem grandes espaços e, conseqüentemente, baixa densidade de novos aduitos próximos aos velhos pais.

Predadores sensíveis à densidade devem ser muito superiores àqueles sensíveis à distância, permitincio que novos adultos surjam longe dos seus pais. Não importa qual a quantidade de semente produzida em um dado ano, ou qual a distância da semente para a árvore mãe, pred’dores sensíveis à distância "perseguem" sementes e plântulas até que suas densidades sejam tão baixas que a procura não seja mais vantajosa. Assim, se sementes ou plântulas encontram-se em pequenas áreas de variáveis densidades, no seu ambiente natural, a sobrevivência de alguma planta deve ser em função do número de plântulas no grupo. Este grupo compreende numerosos insetos que são hospedeiros específicos obrigatórios de sementes e plântulas clispersas, as quais por sua vez, são também hóspedes do hospedeiros específicos facultativos, tais como mamíferos e insetos. Numt;rosos mamíferos da floresta (isto é, queixadas, cotias, pacas, coatis, veados, ratos, etc.) devem subsistir quase que inteiramente de sementes e frutos caídos em certas épocas e eles tendem a concentrar-se em frutos sob uma determinada árvore (Kaufman, 1962). Doenças fúngicas, bacterianas, e de virus (se transportada pelo ar ou por inseto) também devem funcionar como predadores sensiveis à densidade. Como Fournier \& Sálas (1967) acharam, as doenças devem instalar-se via danos ou estragos causądos pelos insetos, embora não seja clara até que grau essas doenças são hospedeiras específicas. Mesmo que elas não seam hospedeiras específicas no estrito senso, devem produzir uma epidemia local porque muitos hospedieiros estão disponíveis na concentração de plântulas em volta da árvore mãe.

Janzen ainda considerá que quando as condiçōes tornam-se mais favoráveis para predadores de sementes e plântulas em um habitat. aquele habitat suportará mais espécies de árvores. porque, nenhuma espécie pode tornar-se suficientemente abundante para competir com a maioria das outras. O óbvio ccrolário é que, como o número de espécies de árvore aumenta em um habitat, a habilidade competitiva interespecífica de plântulas, e plântulas desenvolvidas declina. Onde a árvore está livre de predadores sobre plantas jovens (por parte ou toda vida reprodutiva) ela é um competidor geralmente superior aos fatores fisicos do ambiente. ocorrendo assim condições mais próximas daquelas poucas espécies características de floresta temperada. Para existir em tais stands puros, como plantas de mangue ou alguns legumes, as plantas devem necessitar de sistema de defesa, contra predadores, tais como aqueles produzidos por químicos. Hymenaea courbaril é um exempio de árvore que forma consociação em alguns tipos de florestas secas do México (Langenheim, 1975) e também é dominante ao longo das margens dos rios em muitas áreas onde ela ocorre naturalmente (Langenherm, 1967; Lee \& Langenheim, 1975).

Adicionalmente, em ithas tropicais, a estrututra de população de árvore deve diferir extraordinariamente daquelas de terras firmes adjacentes. Janzen postula que esta estrutura é diferente por causa das pressões dos predadores. Por exemplo, no Havai árvores tais como Trophis (Moraceэe) possuem número denso de plântulas e plântulas desenvolvidas sob a copa da arvore mãe. Estas florestas não possuem roedores nativos e grandes pássaros terrestres que removem as sementes de Trophis debaixo da árvore mãe como é o caso das florestas de baixa elevação da Costa Rica. Leucaena glauca é um outro exemplo: em Costa Rica ela perde $90 \%$ de suas sementes para "bruchid beetles", e em Porto Rico onde "bruchids" não atacam esta espéc: ¿, as sementes são produzidas em tal abundância que as árvores adultas são rodeadas por denso número de plântulas e árvores jovens de idade intermediária. 
A luz das observações e hipóteses de Janzen, é interessante notar que plântulas ae Hymenaea são bem sucedidas sob árvores parentais em ambos os locais estudados neste trabaiho, mesmo considerando-se a elevada diversidade de predadores e parasitas, como é o caso da floresta Amazônica. Na Amazônia Central, sabe-se que é pesada, a predaçãc de sementes de $H$. parvifolia e $H$. intermedia por Rhinochinus, resultando provavelmente no ciclo de produção de dois-três anos. Porém, as plântulas são bem sucedidas sob estas árvores. Em um caso, prósperas plântulas e (ou) plântulas desenvolvidas foram encontradas em uma "falha" de floresta, possivelmente resultado de frutos escondidos por mamíferos. Em geral, entretanto, plântulas foram encontradas sob a copa de árvores mães ou próximas a elas. $\mathrm{Na}$ savana da Venezuela central plântulas desenvolveram-se bem sob a árvore parental ou imediatamente adjacente a ela. Embora não tivessemos encontrado uma forma de avaliar a idade dessas plântulas (seedlings), algumas eram suficientemente grandes (i.s., até 3 metros de altura) para serem consideradas plântulas desenvolvidas (samplings). Embora Rhinochenus ocorra no local estudado na Venezuela, parece (baseado em observações gerais feitas até o momento), que a predação de sementes não é tão grande como na Amazônia. Isto também está de acordo com as observações de Janzen, de que a predação é mais pesada em floresta densa, e menor em locais abertos ou em floresta tropical de estação seca, na Costa Rica.

A questão que então surge é como e porque plântulas tornam-se prósperas sob árvores parentais, não obstante em vários graus, em ambos ecossistemas tropicais. Não há predadores ativos sensíveis à distância e à densidade como tem indicado as observações de Janzen? Certamente as plântulas devem sobreviver às pressões seletivas dos fatores físicos do ambiente, atuando sobre a inteira fisiologia da planta. Plântulas de savana enfrentam as vicissitudes de regimes totalmente diferentes durante as estações úmida e seca. Mesmo na Amazônia Central deve existir mortalidade de plântulas devido a deficiência de água durante certos anos com prolongados períodos secos, excepcionalmente. Entretanto, plântulas sobre- viventes do stress de fatores físicos, tais como disponibilidade de água, igualmente devem encontrar o desafio de predação ou de patógenos. Os resultados preliminares deste estudo sugerem a evolução de uma bem sucedida defesa química da planta em resposta às tais pressōes bióticas. A variabilidade na composição da resina da folha de plântulas na Amazônia deve ser um mecanismo de adaptação, capacitar:doas de crescerem próximas ou imediatamente sob a copa da árvore mãe. Também, se as plântulas de um diferente tipo são estabelecidas com sucesso próximas da árvore mãe (e não mudam ontogeneticamente para o tipo de árvore parental), isto conduzirá à diversidade de tipos entre as plântulas. Diversidade na composição da resina da folha entre adultos é provàvelmente menos significante do que entre plântulas, pois, aquelas podem resistir melhor à predação (exceto desfolhamentos repetidos) do que as plantàs mais jovens. Me nor variabilidade em tipos de resinas da folha nos L.lanos da Venezuela pode possivelmente indicar menor pressão de predador do que na Amazônia. Isto pode ser um fenômeno relativo, porque a variabilidade química tem sido medida em termos de tipos de composição. Estes tipos são caracterizados, primeiramente, pelas diferenças nos compostos maiores, considerando que certos herbívoros e parasitas devem ser impedidos tanto pela presença ou particular concentração de um único composto (mesmo em pequena quantidade) ou efeitos sinergísticos de vários compostos. De estudos preliminares (Stubblebine \& Langenheim, 1977) é sabido que o volume de resina da foIha de Hymenaea courbaril pode afetar taxas de crescimento de pupa, período de pupação e mortalidade, devido a infecçōes virosas de um difundido generalista de legumes, a lagarta da beterraba (Spodoptera exigua). Análises dos efeitos de compostos Individuais, ou particulares combinações entre eles, não foi ainda tentado.

O desafio de predadores ou patógenos pode ser alcançado de várias formas incluindo mudanças químicas. A rutura da defesa química normal de uma planta adulta ou de sua progênie contra predadores ou parasitas deve ocorrer abruptamente em um dado tempo. Quanto mais favorável for o ambiente físico 
para os predadores, mais freqüentemente as defesas químicas das plantas terão de ser modificadas para que elas possam permanecer na comunidade. Estas mudanças químicas devem resultar da variabilidade geneticamente controlada - tanto promovendo suficiente variabilidade em somente uma geração, ou através da evolução do tempo. No caso da composição da resina da folha de Hymenaea, a pressão seletiva é refletida em ambas as diferenças de tipos químicos entre árvore parental e progênie e entre árvores adultas.

Este estudo preliminar abre muitos caminhos de exploraçäo. Infelizmente, o estudo direto do controle genético da síntese de sesquiterpenos é impraticável em árvores, tais como Hymenaea. De outros estudos, nós podemos apenas especular, como é o caso da possibilidade de um sistema genético suficientemente flexível para pərmitir alterações na composição dos sesquiterpenos, os quais seriam então providos de potencial resistência para atacar. Nosso crescente conhecimento dos modelos de variação em tipos de composição vem contribuindo para o melhor entendimentc dos passos biossintéticos através de análises de co-ocorrência (Martin, Langenheim \& Zavarin, 1976a). Por analogia, pode ser que mais tarde possamos considerar alguns compostos sob regulação de um único gen e também estabelecer possíveis relaçōes de dominância (Langenheim, Foster, Lincoln \& Stuobblebine, 1977) .

Muito embora tenhamos evidência de estudos de laboratório de que as resinas da folha de Hymenaea courbaril têm propriedades dissuasivas e possivelmente tóxicas contra a super-generalista "lagarta da beterraba", necessitamos de observações de campo em diferentes ecossistemas, com efeitos reais sobre herbivoros nativos e patógenos. No atual estágio, possuímos somente observações gerais que indicam relativamente pouca atividade herbivora entre plântulas e plântulas desenvolvidas sobreviventes. Isto sugeriria a eficiência das resinas da folha contra ambos predadores sensiveis à distância e à densidade. No entanto, existe alguma evidência para potenciaiidade de epidemia de fungos. Várias centenas de plântulas de $H$. courbaril (todas de composição Tipo II), crescidas em um jardim uniforme de Alejuela, Costa Rica, repeliram o ataque de insetos porém foram sujeitas à epidemia de uma doença fúngica causada por Fomes (Wilson, comunicação pessoal). Estão em andamento no campo estudos que visam aumentar o tamanho da amostragem os quais demonstrarão a variabilidade na progênie, e também, estudos para tentar identificar atividades de vários tipos de predadores e patógenos. Esses resultados serão relatados nas subseqüentes publicações desta série.

\section{AGRADECIMENTOS}

Os autores agradecem as facilidades proporcionadas pelo Instituto Nacional de Pesquisas da Amazônia (INPA), Manaus, Amazonas, Brasil, e pela Estación Biologica de Los Llanos, Calaboza, Venezuela. Particularmente agradecem, também, ao Dr. John Palmer do Projeto Florestal da FAO em Manaus; ao Sr. Joăo Aluísio de Souza, funcionário do INPA, por sua assistência na coleta de plantas na Reserva Ducke e à Dra. Mary Arroyo, do Departamento de Botânica da Universıdad Central da Venezuela, pela ajuda na coleta de plantas junto à Estación Biológica de Los Llanos. Agradecimentos são extensivos aindá a Jonathan Gershenzon, colaborador no trabalho de análises no GLC (GásLíquido-Cromatógrafo) e análises de dados em computador, David E. Lincoln pelos comentários críticcs do manuscrito, Maria Conceição F. Nascimento pela sua assistência na tradução e Mariene Freitas da Silva pelas correçōes do presente trabalho. Os recursos para o estudo foram provenientes de Grants da National Science Foundation (NSF) GB-35267 e BMS $72-02231$.

\section{SUMMARY}

This study is a part of a long-range investigation of the variation in resin composition in the tropical leguminous genus Hymenaea and the possible ecological role of these resins within tropical ecosystems. Although the stem, pod and leaf resins are being studied comparatively, emphasis has been placed on the leaf resin system because of the relative simplicity of the chemistry, opportunities for experimental studies on seedling plants under controlled environmental conditions and expected heavy selection pressures on seedlings in the field. The leaf resins from all species of Hymenaea contain 17-18 sesquiterpene hydrocarbons which vary quantitatively such that six compositio- 
nal types have been recognized. Previous studies of leaf resin composition of 11 species of Hymenaea and 53 populations of the widespread $\mathbf{H}$. courbaril have shown centers of diversity in composition to occur in Amazonia and in southern Brazil in contrast to very little diversity in central and northern South America. Previous investigations of the effects of temperature, light intensity and extreme differences in photoperiod have indicated the low degree of phenotypic plasticity of leaf resin composition in response to physical factors of the environment. Thus it appears that there is strong genetic control over this resin composition.

Genetically controlled patterns in resin composition might be due either to random genetic variation or to genetic variation under selective pressures from various environmental conditions. Although there has been considerable controversy regarding this question in attempts to explain floral diversity generally in tropical rainforests (where only differences in adaphic conditions among physical factors of the environment seem to vary sufficiently to exert significant selective pressures), the role of predators or pathogens as selective agents is increasingly being suggested. Also it has been pointed out that an effective way for plants to meet the challenge of predation is by alterning their chemistry. These are changes which are transmitted genetically. The more favorable the physical environment for predators or parasites, the more frequently in evolutionary time the chemical defenses of the plant will have to be modified through genetic changes if the plant is to be successful in the community. Thus one could conclude that recombination systems in higher plants in tropical rainforests and species are subject to directional pressures from herbivores and pathogens in an "evolutionary arms race". Thes agents of selection favor improvement of defensive posture on the part of the plant hosts which will be balanced in turn by counter adaptation by the predator or parasite.

Tropical floras appear to be better endowed than temperate ones with secondary chemicals $\mathrm{w}$ hich may function defensively. The rate at which chemical resistance to herbivores is achieved is dependent upon a variety of conditions, such as the number of genes controlling the chemistry, dominance of the traits, relative general fitness, the tolerance of the plant, size of the herbivore population, etc. Gene substitution at one or few loci may alter the secondary metabolism of a plant in such a way that it becomes resistant to a given herbivore, and alleles for resistance have been found to be dominant over those for susceptibility.

Perhaps too much emphasis in the past has been given to the role of insect predators of plants because the chemical defenses of most plants probably will be coevolutionary with a variety of predators and parasites. However, relatively little is known at present about the relative importance of selective pressures of different kinds of herbivores in evolution of the defenses of plants. Also recent research has indicated that chemical defenses of plants may have far-reaching affects in natural ecosystems, i.e., chemical defense systems against herbivores and pathogens may very as a function of plant persistance and abundance, which in turn affects the ecology of herbivores and their plant foods in different ecosystems.

In this study leaf resin composition of Hymenaea was compared between parent trees and their progeny in three species: $\mathbf{H}$. intermedia and H. parvifolia from the rainforest ecosystem at Reserva Ducke near Manaus, Amazonas, Brazil and $\mathbf{H}$. courbaril from the savanna ecosystem at Laguna de Los Patos adjacent to the Estacion Biologica de Los Llanos near Calabozo, Guarico, Venezuela. Gas liquid chromatographic analyses were made of resins from leaves collected from seedlings and saplings growing under the canopy of the tree as well as from saplings grown in the greenhouse from seeds originating from some of the same parent trees. Age of the seedlings collected in the field are unknown but specimens from $\mathbf{H}$. intermedia and $\mathbf{H}$. parvifolia are known from phenological data to be at least three years old. Plants of $\mathbf{H}$. parvifolia grown in the UCSC greenhouse vary in age from 6-10 years. Three chemical types were represented among the adult trees but only one type appeared among the progeny under each parent tree. For example, the parent tree of $\mathbf{H}$. parvifolia have leaves with Type I resin composition and all of the surviving seedlings have Type V. However, greenhouse grown saplings of H. parvifolia from seed collected from the same parent tree had three types (I, II and V). An anticipated less variable pattern occurred in $\mathbf{H}$. courbaril from the savanna ecosystem. Both parent tree had leaves of Type II composition with a large number of both seedlings with leaves also of Type II. One tree also had saplings, as well as seedlings, which were also Type II. This predominance of Type II composition of seedlings agrees with previous extensive analysis of greenhouse grown seedlings from various populations of $\mathbf{H}$. courbaril in Central and northern South America. Six other adult trees were also characterized by Type II composition.

It is not known whether leaf resin composition changes with ontogeny of the tree from seedling to adult. In some cases, the only type found at various stages of ontogeny has been Type II, which is the most common and generally the most variable type. In any event, whether or not chemistry changes with ontogenetic changes, results 
from this study indicate that under tropical rainforest conditions there is striking difference in leaf resin composition between parent trees and their progeny. It is in this habitat that the greatest diversity of predators and parasites would be expected. Considerably less variability occurs between parent tree and progeny in the savanna conditions in Venezuela. Here it might be assumed that diversity of herbivores and pathogens would be less than the rainforest.

Research in several areas in the tropics has incicated that both distance - and density - responsive predators will tend to eliminate progeny under the canopy of the parent tree or close to it. Therefore it has been assumed that any strategy that enables a tropical tree to disperse its seed away from the parent is likely to help ensure the success of the progeny. On tropical islands, where there are fewer predators and parasites than on mainland sites, seedlings and saplings are often prolific under and adjacent to parent trees. In light of these observations, it is interesting that Hymenaea seedlings are successful under parent trees in both mainland sites studied in this paper, and even under the assumed peak diversity of predators and parasites in the Amazonian rainforest.

The question then arises as to why seedlings of these species of Hymenaea are successful under their parent trees, albeit in varying degrees in the two tropical ecosystems. The preliminary results from this study suggest evolution of a successful chemical defense by the plant in response to predation (probably both distance - and densityresponsive). Variability in leaf resin composition of seedlings may be an adaptive mechanism enabling them to grow close to or immediately under the canopy of the parent tree in Amazonia.

Also, if the seediings of a different chemical type are successful in becoming established near the parent (and do not change ontogenetically to the type of the parent), this will lead to diversity of types among the adult trees. Diversity of leaf resin composition among the adults probably is of less significance than among the seedlings since the adults can withstand predation (except repeated defoliation) better than younger plants. Less variability in leaf resin types in the llanos might possibly indicate less predator pressures there than in Amazonia. However, this might well be a relative phenomenon because the chemical variability has been measured in terms of chemical types. These types are characterized primarily by the major compounds, whereas certain kinds of herbivores and parasites might be deterred either by the presence or particular concentration of a compound (even in small quantities) or synergistic effects of several compounds. From previous studies it is known that bulk leaf resins from Hymenaea can affect the pupal weight, length of time to pupation and mortality due to viral infection of the widespread legume generalist, beet army worm. Analyses of the effects of single components or particular combinations of them have not been attempted as yet.

This preliminary study opens many doors for exploration. Direct study of the genetic control of sesquiterpene synthesis is infeasible in such trees as Hymenaea. Our increasing knowledge of the patterns of variation in leaf resin composition is aiding our understanding of the biochemical pathways through analysis of co-occurrence of the sesquiterpenes. Perhaps by analogy we can later speculate as to whether certain compounds are under single gene regulation and possible dominance relationships.

In subsequent papers in this series we plan to include another Amazonian species (H. courharil v. subsessilis) and a more detailed examination of the important central Amazonian species $\mathbf{H}$. intermedia and compare them with two species in southern Brazil (H. stigonocarpa in the cerrado and $\mathbf{H}$. courbaril v. stilbocarpa in riparian forests).

\section{BIBLIOGRAFIA CITADA}

ARaujo, V.C. DE

1970 - Fenologia de essências florestais amazônicas. Bol. INPA Pesquisas Florestais, $4: 1-25$.

Ashton, P.S.

1969 - Speciation among tropical forest trees: some deductions in light of recent evidence. Biol. J. Linnean Soc. London, $1: 155-196$.

BAWA, K.S.

1974 - Breeding systems of tree species of a lowland tropical community. Evol., 28 : 85-92.

Black, G.; Dobzhansky, TH. \& Payan, C.

1950 - Some attempts to estimate species diversity and population density of trees in Amazonian forests. Bot. Gaz. (Craw. fordsville), $3: 413-425$.

CONNELL, J.H.

1971 - On the role of natural enemies in preventing competitive exclusion in some marine animals and in rain forest trees. In: Proceedingsg of the Advanced Stuciy Institute on Dynamics of Numbers in Populations, Oosterbeck, 1970 (ed. P.J. den Boer and G.R. Gradwell); Centre for Agricultural Publishing and Documentation, Wageningen : 298-312. 
CRUz ACOsTA, A. DE LA

1964 - A preliminary study of organic detritus in a tropical forest ecosystem. Revista Biol. Trop., $12: 175-185$.

Dacosta, C.P. \& Jones, C.M.

1961 - Cucumber beetle resistance and mite susceptibility controlled by bitter gene in Cucumis sativus L. Science, 172: $1145-1146$.

EIdMANN, H,

1943 - Zur ökologie der Tierwelt. Beitr. Ko. lonialf., $2: 25-45$.

FEENY, P.P.

1975 - Biochemical coevolution between plants and their insect herbivores. In: L.B. Gilbert and P.H. Raven eds, - Coevo. lution of Animals and Plants., Univ, of Texas Press, Austin : 3-19.

1976 - Plant apparency and chemical defense. In: J. Wallace and R. Mansell, eds. Biochemical Interaction Between Plants and Insects. Recent Advances in Phyto. chemistry, Vol. 10:1-40.

Fittkau, E.J. \& Klinge, H.

1973 - On biomas and trophic structure of the central Amazonian rain forest ecosystem. Biotropica, 5(1): 2-14.

Fournier, L.A. \& SAlas, S.

1967 - Tabla de vida el primer ano de la poblacion de Dipterodenron costaricense. Radk. Turrialba, $17: 348-350$.

GRUBB, P.J.

1977 - The maintenance of species - richness in plant communities: The importance of the regeneration niche. Biol. Rev., 52 : 107-145.

JANZEN, D.H

1968 - Host plants as islands in evolutionary and contemporary time. Amer. Nat. $102: 592-595$

1969 - Seed-eaters versus seed size, number and dispersal. Evol., $23: 1-27$.

1970 - Herbivores and the number of tree species in tropical forests. Am. Nat. 104(940) : 501-528.

1971 - Scheelea, Hymenaea and Sickingia and their seed predators. OTS News, 71(5): 3-4.

1973 - Tropical agroecosystems. Science, 182 : 1212-1219.

Kaufman, J.H.

1962 - Ecological and social behavior of the coata Nasau nasau on Barro Colorado Island, Panama. Univ. of Calif. Publ. Zool., 60 : 95-222.
KLINGE, H. \& Rodrigues, W.A.

1968 - Litter production in an area of Amazo. nian terra firme forest. Amazoniana, I : 287-302; II : 303-310.

KOOLSTRA, E.

1961 - Red spider mite tolerance in cucumber. Euphytica, $20: 47-51$.

KULMaN, H.M.

1971 - Effects of insect defoliation on tree growth and mortality of trees. Ann. Rev. Entomol.

LANGENHEIM, J.H.

1964 - Present status of botanical studies of ambers. Harvard Bot. Mus. Leaflets, 20(8) : 225-287.

1966 - Botanical source of amber from Chiapas, Mexico, Ciencia, $24: 201-211$.

1967 - Preliminary investigations of Hymenaea courbaril as a resin producer. $\mathbf{J}$. Am. Arb., 48(3): 203-229.

1969a-Amber: a botanical inquiry. Science, $163: 1157-1169$.

1969b - Evolution of resin-secreting trees. XI. International Bot. Congress Abstracts: 121.

1972 - Origin of fossilized resin and its relation to forest history in northeestern Angola. Publicaçôes Culturais Campa. nha de Diamantes de Angola, 85:15-36.

1973 - Leguminous resin-producing trees in Africa and South America. In B.J. Meggers, E.S. Ayensu \& W.D. Duckworth, eds. - Tropical Forest Ecosystems in Africa and South America: A Comparative Review. Smithsonian Press, Washington, D.C.

1975 - Role of the tropics in evolution of resin-producing trees. Proc. XII International Bot. Congress, Leningrad.

LANGenheim, J.H.; Lee, Y.T. \& Martin, S.S.

1973 - An evolutionary and ecological perspective of Amazonian Hylaea species of Hymenaea (Leguminosae: Caesalpiniodeae). Acta Amazonica, 3(1) : 5-38.

LANGenheim, J.H.; Foster, C.; Lincoln, D.E. \& STUBBLEBINE, W.H

1977 - Comparison of resin composition in leaf blade petiole, and primary stem in $\mathbf{H}$. courbaril and $\mathbf{H}$. verrucosa. Biochem. Syst. and Ecol.

Langenheim, J.H.; Stubblebine, W.H.; Foster, C, \& LINCOLN, D.E.

1977 - The type concept in leaf resin composition in Hymenaea. Unpubl. Manuscript. 
LEChtHALER, $\mathrm{R}$.

1956 - Inventário das árvores de um hectare de terra firme da Reserva Florestal Ducke, Município de Manaus, Public. do INPA: Série Botânica, 3.

LEE, J.A.

1965 - The genomic allocation of the principal foliar bland loci in Gossypium hir. sutum and Gossypium barbadina. Evol., 19 : $182-188$.

LeE, J.A.; Cockerham, C.C. \& SMith, F.H.

1968 - The inheritance of gossypol level in Gossypium. I. Additive dominance, epistatic and material effects associated with seed gossypol in two varieties of Gossypium hirsutum L. Genetics, 59 : 285-298.

LEE, Y.T. \& LANGenHEIM, J.H.

1975 - Systematics of the genus Hymenaea (Leguminosae, Caesalpinioideae, Detarieae). Univ. of Calif. Public. in Botany, $69: 109 \mathrm{pp}$.

LEVIN, D.A.

$1975 \mathrm{a}$ - Post pressure and recombination systems in plants. Am. Nat., 109:437-451.

1975b - Alkaloid-bearing plants: an ecogeographic perspective. Am. Nat., $110: 261-284$.

MANN, G.

1968 - Die Ökoyisteme Sudamerikas: 171-229. In - E.J. Fittkau, J. Illies, H. Klinge, G.H. Schwase and H. Sioli, eds. - Biogeography and Ecology in South America, Vol. 1. In Monographiae Biological 18. W. Juhk N.V. The Hague.

MARTin, S.S.; LANGenheim, J.H. \& Zavarin, E.

1972 - Sesquiterpenes in leaf pocket resin of Hymenaea courbaril. Phytochem., 11: 3049-3051.

1974 - Quantitative variation in leaf pocket resin composition in Hymenaea courbaril. Biochem. System and Ecol., 3: 760-787.

1976a - Biosynthesis of sesquiterpenes in Hymenaea inferred from their quantitative co-occurrence. Phytochem., 15:113-119.

$1976 \mathrm{~b}-$ Quantitative variation in leaf pocket resin composition in Hymenaea. Biochem. System. and Ecol., 4 : 181-191.
ODum, H.T. \& RuIZ-REyes, J.

1970 - Holes in leaves and grazing control mechanism. In: H.T. Odum and R.F. Pigeon, eds. - A Tropical Rain Forest. A Study of Irradiation and Ecolugy in El Verde. Division of Technical Information, U.S. Atomic Energy Commission, Oak Ridge, Tenn.: 160-180.

PIRES, J.M.; DOBZhansky, TH, \& Black, G.

1953 - An estimate of the numbers of species in an Amazonian forest community. Bot. Gaz. (Crawfordsville) 6:467-477.

RhoAdes, D.F. \& CATEs, R.G.

1976 - Toward a general theory of plant herbivore chemistry. In: J. W. Wallace and R.L. Mansell, eds. - Biochemical Interaction Between PIants and Insects. Recent Advances in Phytochemistry, 10: 168-213.

ROCKWOOD, L.L.

1973 - The effect of defoliation on seed production in six Costa Rican tree species. Ecol., 54 : 1363-1369.

RODRIGUES, W.A.

1967 - Inventário florestal piloto ao longo da estrada Manaus-Itacoatiara, Estado do Amazonas. Dados preliminares. In: H. Lent, ed. - Atas do Simpósio Sobre a Biota Amazônica 7. (Botânica) : 257-267. Conselho Nacional de Pesquisas. Rio de Janeiro.

Stubelebine, W.H.; Langenheim, J.H. \& Lincoln, D.E.

1975 - Vegetative growth and leaf resin composition in Hymenaea courbaril under photoperiodic extremes. Biochem. Syst. and Ecol., $3: 219-228$.

Stubrlebine, W.H.; \& LANGenheim, J.H

1977 - Effects of Hymenaea courbaril leaf resin on the generalist herbivore Spodoptera exigua (Beet army worm). J. Chem. Ecol., 3.

TAKEUCHI, M.

1961 - The structure of Amazonian vegetation. II. Tropical rain forest. J. Fac. Sci. Univ. Tokyo Section: 3 Bot., 8 1-26.

TURNER, J.R.

1967 - Why does the genotype not congeal? Evolution, 21 : 645-656

WHITTAKER, R.H.

1969 - Evolution of species diversity in plant communities. Brookhaven Symp. Biol., $22: 178-185$. 